\title{
Immobilized Yeast Bioreactor Systems for Continuous Beer Fermentation
}

\author{
Murthy Tata,* Patricia Bower, Susan Bromberg, Dick Duncombe, J eff Fehring, \\ Vera Lau, David Ryder, and Paul Stassi
}

Miller Brewing Company, 3939 West Highland Boulevard, Milwaukee, Wisconsin 53201

\begin{abstract}
Two different types of immobilized yeast bioreactors were examined for continuous fermentation of high-gravity worts. One of these is a fluidized bed reactor (FBR) that employs porous glass beads for yeast immobilization. The second system is a loop reactor containing a porous silicon carbide cartridge (SCCR) for immobilizing the yeast cells. Although there was some residual fermentable sugar in the SCCR system product, nearly complete attenuation of the wort sugars was achieved in either of the systems when operated as a two-stage process. Fermentation could be completed in these systems in only half the time required for a conventional batch process. Both the systems showed similar kinetics of extract consumption, and therefore similar volumetric productivity. As compared to the batch fermentation, total fusel alcohols were lower; total esters, while variable, were generally higher. The yeast biomass production was similar to that in a conventional fermentation process. As would be expected in an accel erated fermentation system, the levels of vicinal diketones (VDKs) were higher. To remove the VDKs, the young beer was heat-treated to convert the VDK precursors and processed through a packed bed immobilized yeast bioreactor for VDK assimilation. The finished product from the FBR system was found to be quite acceptable from a flavor perspective, albeit different from the product from a conventional batch process. Significantly shortened fermentation times demonstrate the feasibility of this technology for beer production.
\end{abstract}

\section{Introduction}

Traditionally, beer fermentations have been conducted as batch processes. Although the advantages of a continuous fermentation process are well recognized, there are relatively few continuous brewing processes in operation, the most notable and perhaps the most successful being some breweries in New Zealand (1). Several different schemes of continuous free cell fermentation processes have been tried at various scales of operation as early as the 1960s (2), but most of these did not remain commercially viable. These systems fell into disfavor for several reasons such as the increased complexity of operations required relative to the traditional "fill and shut" batch process, the dangers of culture contamination, a general "instability" of the system from an operations standpoint, unrealized cost and productivity advantages in the process plant, and the fear of genetic drift of the yeast strain.

Continuous systems based on immobilized yeast technol ogy seem to be more advantageous from a commercial operations standpoint because of the potential for high fermentation rates afforded by the high cell concentrations of yeast in the bioreactor. There is al ready a vast amount of literature discussing immobilized cell technology for other fermentation processes that have shown significant process economic and quality advantages over the batch process. The matrixes used for immobilizing the yeast cells include gel type materials such as al ginate,

* To whom correspondence should be addressed. Telephone: (414)931-2199. Fax: (414)931-2506. E-mail: Tata.Murthy@MBCo.com. as well as porous structures that allow the matrix to shed viable cells as the immobilized biomass grows. Among the latter are porous matrixes such as porous glass beads, ceramic beads $(3-5)$, chitosan $(6,7)$, polymeric foam $(8$, 9 ), and even loofa sponge (10). While the relative instability of the gel matrixes has been a challenge to overcome, it appears that at least one brewer in N orth America is actively developing this technology (11). Immobilization of the yeast cells can impact the cell physiology, especially those related to brewing functions in both positive and negative ways (12-14). These physiological effects could be attributed in part to the diffusional limitations for yeast nutrients as well as for substrates and products of fermentation $(15,16)$. It appears, however, that the diffusivities for sugars in $2 \%$ alginate membranes are similar to those in water in either the presence or absence of cells in the gel (17).

In addition to the choice of the carrier material, the type of bioreactor chosen can have far-reaching implications on the success of the technology. Early systems used to their advantage the fact that some yeast strains form strong flocs (bioparticles) that can remain in the fermentor in the face of continuous wort dilution and beer harvest $(2,18-20)$. Systems based on this technology, although successful initially, proved to be unstable in the long term. Recent techniques include packed bed reactors that seemed very promising on the smaller scale (21). Larger scale systems proved very difficult to operate properly for three main reasons. First, the carbon dioxide generated during fermentation would accumulate in the bed, forming dry spots in the reactor and lifting the bed. 


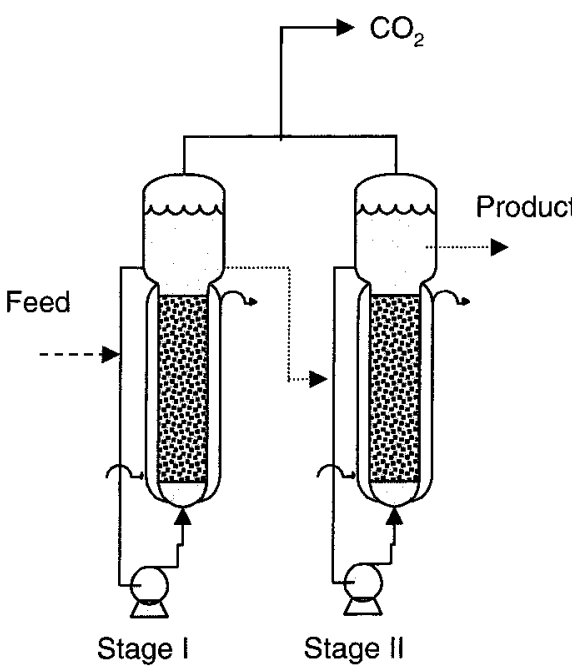

(a) Fluidized (FBR) system $7.5 \mathrm{~L}$ each Stage

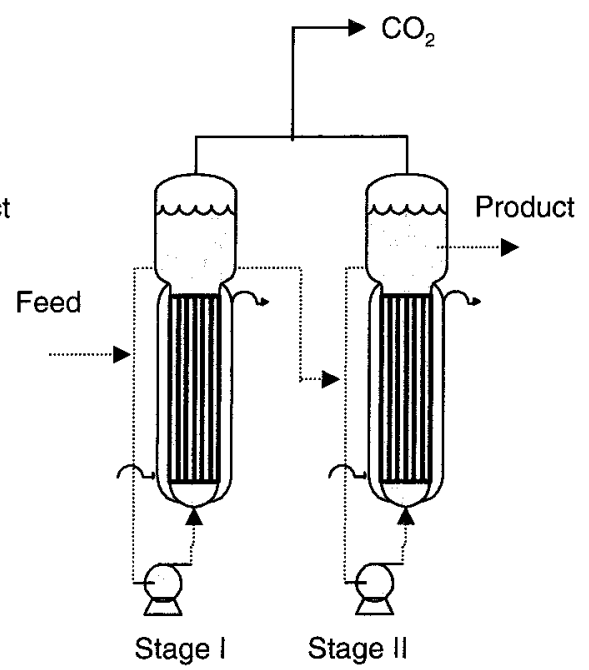

(b) Cartridge (SCCR) system $2.2 \mathrm{~L}$ each Stage

\section{- Stainless steel tubing \\ Silicone elastomer tubing}

Figure 1. Schematic of the two immobilized yeast reactor systems: (a) fluidized bed reactor (FBR) system, (b) silicon carbide cartridge reactor (SCCR).

Second, severe liquid-phase channeling would create dry spots, seriously compromising biomass viability. Third, achieving adequate heat transfer (cooling) in such packed bed reactors seemed a daunting task (22). More recent and perhaps improved systems employ some type of forced circulation either in a packed bed reactor or in a fluidized bed reactor to allow for the $\mathrm{CO}_{2}$ to escape and also address the channeling and heat-transfer problems. Because of the large recirculation rates (i.e., recycle ratios) required in these systems, they operate more like a stirred tank reactor (CSTR) than a plug flow reactor (PFR). The plug flow profile possible in the packed bed systems is preferable from a product quality standpoint because it simulates most closely the temporal progression of a batch fermentation (cell growth, extract consumption, ester formation, etc). In a single-stage CSTR, the fermentation cannot be carried out to completion except at prolonged residence times. In addition, the product quality is not optimally balanced in a CSTR for the processing of a complex network of series and parallel reaction steps as in a batch reactor $(23,24)$. A minimum of two CSTR stages are clearly required in any forced circulation (recycle flow) system to ensure that these problems are adequately addressed.

The present paper discusses two such recirculated systems for continuous beer production from a high specific gravity wort. One of these, the silicon carbide cartridge reactor, can be regarded as a forced-circulation packed bed system except for the fact that the "packed bed" is itself a monolith of porous silicon carbi de ceramic cartridge with flow channels machined into the body as described in the following section. The second system is based on a gently fluidized bed using porous glass beads as the yeast carrier. The kinetics of fermentation and the product quality attributes for each system and their impact on fermentation development are discussed.

\section{Materials and Methods}

A brewing strain (MY9496) of Saccharomyces cerevisiae (S. uvarum) from the Miller culture collection was used in all the experiments. The wort was prepared 55\% from malt and $45 \%$ from a corn adjunct that was nearly all carbohydrate. The wort had an extract content of $16^{\circ} \mathrm{P}$ (degrees Plato) original gravity (i.e., 16\% w/w). Sterile wort was stored under a sterile $\mathrm{CO}_{2}$ counter pressure (ca 5 psig) and at a temperature of $1.5^{\circ} \mathrm{C}$ until ready for use. The reactor feed tanks ( $20 \mathrm{~L}$ capacity) were also maintained under $\mathrm{CO}_{2}$ counter pressure during the experiments (at ca. $0.2-0.5$ psig), and were maintained at approximately $1.5{ }^{\circ} \mathrm{C}$. Periodically, fresh wort from storage was transferred aseptically into the feed tanks. Unless indicated otherwise, the fermentation temperature was $15.6^{\circ} \mathrm{C}$.

Samples were withdrawn from the reactors aseptically and were analyzed for specific gravity (Anton Paar, DMA 58), $\mathrm{pH}$ (Beckmann), yeast cell counts (hemocytometer), and cell viability (methylene blue staining). The extract content of the broth at various degrees of fermentation was calculated as the apparent extract from the specific gravity measurements, using the tables of ASBC (25). These apparent extract contents are reported in units of degrees Plato, (i.e., \% w/w) as is common in the brewing industry. Periodically (at least once a month), the samples were plated on Universal Beer Agar (26) supplemented with $3 \mu \mathrm{g} \mathrm{mL}^{-1}$ cycloheximide to check for any microbiological and "wild yeast" contamination. Volatile compounds in beer were analyzed by headspace gas chromatography (27).

Reactor Systems. Schematics of the two reactor systems are depicted in Figure 1. Each system is discussed below. The fluidized bed reactors (FBRs) used in this study were similar to the single-stage system studied by Breitenbucher and Mistler under conditions of minimal fermentation employed for the production of nonalcoholic beer (28). Similar glass beads were employed in an immobilized yeast beer maturation process (29). The silicon carbide cartridge reactors (SCCR) were very similar to those devel oped by Masschelein and co-workers and used in various configurations for continuous fermentation, production of nonalcoholic beer $(30,31)$, and maturation of "green" beer (32). It is of inter est to note that a somewhat similar system has been successfully 
developed at the Georgia Institute of Technology for the production of fuel/industrial al cohol in Brazil (33).

Flui dized Bed Reactors. Each stage of the FBRs was 7.5 L, and contained spherical, porous glass beads as a support for immobilizing the yeast cells. At the system start up, each reactor was loaded with 3-3.5 $\mathrm{L}$ of fresh porous glass beads (Siran, Schott Engineering, Germany). The beads employed were 1-2 $\mathrm{mm}$ in diameter, with a porosity of $60 \%$, a surface area of $87 \mathrm{~m}^{2} / \mathrm{L}$, and a pore size of less than $300 \mu \mathrm{m}$. A stainless steel centrifugal pump recirculated the fluid in the reactor and maintained fluidization of the glass beads carrier. A 2 in. polypropylene ball in the bottom cone served as a flow distributor and a check val ve to prevent escape of the beads into the pump casing. The minimum fluidization velocity for the beads in water was determined in a separate "cold-flow" experiment to be ca. $0.3 \mathrm{~cm} \mathrm{~s}^{-1}$ at ambient temperatures. The reactors were operated at ca. 30\% bed expansion. The fluid vel ocity was adjusted by the fluidization pump speed control using variable frequency inverters for the ac induction motors driving the pumps.

Silicon Carbide Cartridge Reactors. Each stage of the SCCR was $2.25 \mathrm{~L}$, and contained a $0.9 \mathrm{~m}$ long cylindrical porous silicon carbide cartridge for yeast immobilization (Meura-Delta, Belgium). The cartridge was $25 \mathrm{~mm}$ in diameter with 19 cylindrical channels of $2.5 \mathrm{~mm}$ i.d. each drilled al ong the length of the cartridge. The matrix had a $60 \%$ void volume and a pore size distribution encompassing $30 \mu \mathrm{m}$ on the surface to 150 $\mu \mathrm{m}$ in the interior. The cartridges were inserted into the reactor and held in place at the ends with silicone O-rings, leaving an annular space between the reactor wall and the external surface of the matrix. The reactors were equipped for recirculation with a peristaltic pump that drew liquid from the top chamber of the reactor and pumped it into the bottom section. The system was plumbed in such a way that the liquid was circulated through the outer annulus as well as the 19 internal channels of the cartridge.

Reactor System Startup. Fluidi zed Bed Reactors. A fresh charge of the carrier beads was loaded into the reactors at the beginning of the experiments. Prior to inoculation, the reactors containing fresh carriers were washed by rinsing with at least 20 volumes of dei onized (DI ) water, and sterilized at ca. 5 psig of saturated steam for $1 \mathrm{~h}$. After the system cooled, the reactors were charged with sterile DI water. Fluidization was established, and the temperature control system was then activated to control the temperature at $4.4{ }^{\circ} \mathrm{C}$. Each reactor was separately inoculated by pumping in approximately $3 \mathrm{~L}$ of concentrated yeast slurry (greater than $10^{\circ} \mathrm{cells} / \mathrm{g}$ wet weight) through the sampling/feed ports on the recirculation line. After yeast addition, the system was left in the recirculation mode overnight at $4.4{ }^{\circ} \mathrm{C}$. Wort feed was then initiated and maintained for $12 \mathrm{~h}$ at a rate corresponding to a $5 \mathrm{~h}$ residence time to flush out the majority of the free (i.e., nonimmobilized) yeast cells from the reactor. The fermentation process was initiated by raising the temperature of the reactors to $15.6^{\circ} \mathrm{C}$. The feed rate was later adjusted to achieve the desired degree of attenuation (fermentation) which was ca. $0.20-0.23 \mathrm{~L}$ $\mathrm{h}^{-1}$. Operation as a two-stage system was initiated by connecting the feed tubing of one of the reactors (designated as stage II) to the harvest line of the other (stage I). The volume in each reactor was maintained constant by means of an overflow harvest mechanism driven by a peristaltic pump that ran continuously. The same peristaltic pump was used to drive feeding and harvesting mechanisms during the operation of the two-stage pro- cess. The tubing used for the harvest lines was of a larger diameter than the feed tubing, and therefore a considerable amount of $\mathrm{CO}_{2}$ gas that was generated in the bioreactor was drawn into the harvest line to make up for the line volumetric capacity $\left(0.3-1 \mathrm{~L} \mathrm{~h}^{-1}\right)$. The $\mathrm{CO}_{2}$ generation rate was large enough (ca. $5 \mathrm{~L} \mathrm{~h}^{-1}$ ) to prevent the ambient air from being drawn into the reactor because of this mechanism.

The final operating steady state of the reactor system seemed to be quite independent of the inoculation protocol. F or example, in a different inoculation procedure, wort feed to the reactors was initiated at the final operating level directly, bypassing the explicit free cell washout conditions. It was found that the system approached the same steady state as with the protocol described above.

For the determination of the residence times distribution in the FBR system, a lactose pul se was injected into stage I. Lactose is not metabolized by brewing yeast and, therefore, is a good choice for tracer studies. From FBR stage I, $350 \mathrm{~mL}$ of beer was removed. Then, $350 \mathrm{~mL}$ of sterile solution containing $75 \mathrm{~g}$ of lactose was injected into stage I. At different times following injection as well as prior to lactose injection, samples were withdrawn from each reactor and analyzed for lactose concentration using an enzyme-based electrochemical sensor (YSI Instruments). The instrument had a background response that was constant but different for each stage of the system when no lactose was present. These background values were subtracted from the measured values for the respective stages to obtain actual lactose level in the samples. The concentrations were normalized by dividing the concentration by the value at time zero in stage I, which was obtained 15 min after injection.

Silicon Carbide Cartridge Reactors. After the system was assembled, the reactors were cleaned using the following procedure: cold water rinse, hot water, hot $\mathrm{NaOH}$ (ca. $75^{\circ} \mathrm{C}, 0.01 \mathrm{~N}, \mathrm{pH} \leq 12$ ), followed by cold water, oxidizing solution (peracetic acid + hydrogen peroxide solution, $1 \%$ ), cold water, enzyme cleaning with $2 \%(\mathrm{w} / \mathrm{v}$ ) cellulanase (Solvay, TP 4000) in $0.5 \mathrm{M}$ sodium acetate buffer ( $\mathrm{pH} 4.2$ ), cold water, hot caustic, hot water, and finally steam sterilization at ambient pressure for 1 h. After the system cooled, each reactor was colonized separately. Aerated diluted wort ( $\left.11^{\circ} \mathrm{P}\right)$ was inoculated with yeast at ca. $(10-12) \times 10^{6} \mathrm{cell} / \mathrm{s} / \mathrm{mL}$, and the suspension was pumped into the reactors. The temperature was then set to $15.6{ }^{\circ} \mathrm{C}$ and the system left to recirculate without fresh wort feed for $24 \mathrm{~h}$ at ca. 20 reactor volumes per hour. At the end of $24 \mathrm{~h}$, two-stage operation was initiated at the desired feed rate by starting fresh wort feed to stage I and connecting the stage I harvest line to stage II as a feed.

Cell Mass Loading. The extent of immobilization matrix colonization was determined as follows. It was possible to draw samples of beads from the FBR system during operation. Samples were drained of the free entrained liquid, weighed, and dried at $85{ }^{\circ} \mathrm{C}$ to a constant weight (typically reached within $48 \mathrm{~h}$ ). The quantity of moisture evaporated was used together with the extract content in the entrained liquid (from the reactor operating extract level) to cal culate the amount of entrained extract/unfermented solids in the dry matter. The dry beads were then slowly incinerated in a muffle furnace at $400{ }^{\circ} \mathrm{C}$ to burn off the organic matter and weighed again. To obtain the cell dry weight in the sample, the extract residue obtained above was subtracted from the total dry matter obtained in the preceding step. A similar procedure was used to estimate dry 


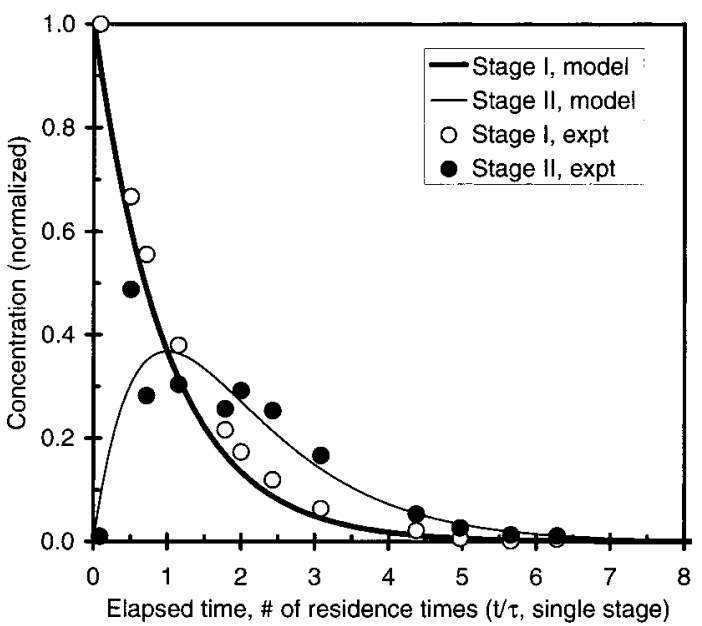

Figure 2. Residence time distribution of the lactose tracer impulse injected into stage I of the FBR system. The experimental data (normalized) are indicated by symbols; the lines represent a two-stage CSTR mathematical model simulation.

cell mass in the SCCR cartridges, with one differencethe cartridges were not incinerated; instead, the tare weight of the cartridge was obtained prior to instal lation in the system.

Cell Mass Yield Coefficient, $\mathbf{Y}_{\mathbf{X} / \mathbf{O}_{2}}$. Cell growth in fermentations was limited by the levels of available oxygen. The sources of oxygen ingress into the systems were the various el astomer tubings employed (cf. Figure 1). Of these, the most permeable tubing was the silicone feed tubing used in the FBR system. To determine the cell growth yield coefficient from oxygen supply, $\mathrm{Y}_{\mathrm{x} / \mathrm{O}_{2}}$, the dissolved oxygen (DO) level in the feed wort was measured off-line. The wort feed connection at FBR stage I was disconnected, and the sterile wort was routed to a flow cell containing a polarographic dissolved oxygen probe (Ingold/Mettler-Toledo). The flow cell (15 mL) contained a small magnetic stir bar $(1 \times 0.2 \mathrm{~cm})$ that was stirred with an external drive. Care was taken to remove any trapped bubbles from the flow cell. At the normal operating flow rate $\left(0.20-0.23 \mathrm{~L} \mathrm{~h}^{-1}\right)$, the DO in the feed wort was thus measured at $4.9 \mathrm{mg} \mathrm{L}^{-1}$. Considering that the cell growth in the FBR system was ca. 4.5 $\mathrm{g} \mathrm{L}^{-1}$, the cell yiel d coefficient was calculated as $4.5 \mathrm{~g}$ of cells $/ 4.9 \mathrm{mg}$ of $\mathrm{O}_{2}=$ ca. 950 .

\section{Results and Discussion}

The reactor systems were operated without encountering microbiological contamination problems for as long as 1 year. In general, the operation of the FBR system was more stable than the SCCR system.

Residence Time Distribution. Once steady-state operation was achieved, a lactose tracer study was initiated to determine the residence time distribution (RTD) in the FBR system. Figure 2 shows the residence time distribution of a lactose pulse injected into stage I of the FBR system. Lactose is not metabolized by the yeast and therefore is an ideal choice for use as a tracer for the RTD study. As seen in Figure 2, these data show reasonable agreement with a two-stage ideal CSTR RTD model for a single-stage residence time of $36 \mathrm{~h}$. The SCCR system was operated at a higher internal recirculation rate (recycle ratio) than the FBR system, and therefore, it can also be regarded as a two-stage CSTR hydraulics system.

Extract Consumption. The changes in the apparent extract content in the reactors at feed rates corresponding
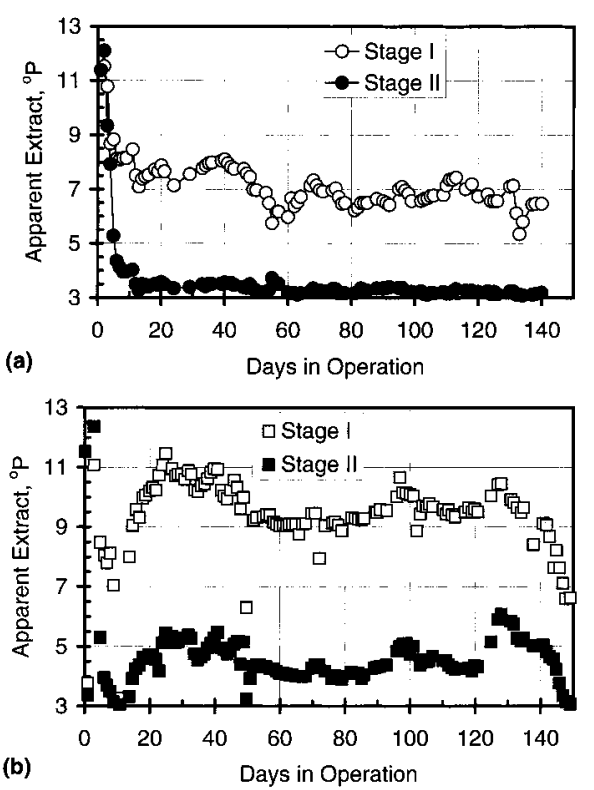

Figure 3. Extract consumption. The extract content in each stage of the two systems is shown as apparent extract (\% w/w). The residence time in each stage is between 36 and $40 \mathrm{~h}$ for either system. (a) FBR system: about $70 \%$ of the total fermentable extract is consumed in stage I. (b) SCCR system: only about $45 \%$ of the total fermentable extract is consumed in stage I.

to single-stage residence times of ca. $36-40 \mathrm{~h}$ is shown in Figure 3. In either system, ethanol and carbon dioxide (not measured, but estimated by stoichiometry) were the major products of metabolism, accounting for $94 \%$ of the extract consumed. Cell growth accounted for about $4 \%$ of the extract. While no attempt was made to close material balance, it is conceivable that some of the remaining $2 \%$ extract went to produce other minor products of metabolism. In the FBR system, the $16^{\circ} \mathrm{P}$ wort was attenuated to ca. $7^{\circ} \mathrm{P}$ apparent extract in stage I and ca. $3.2^{\circ} \mathrm{P}$ in stage II (Figure 3a). The limit attenuation for this particular wort is about $3{ }^{\circ} \mathrm{P}$ (apparent extract). Therefore, fermentation was nearly completed in the FBR system. About $70 \%$ of carbohydrate consumption occurred in stage I, and the rest was consumed in stage II.

Figure $3 \mathrm{~b}$ shows the extract consumption profile for the SCCR system. Stage I attenuated the $16^{\circ} \mathrm{P}$ wort to ca. $9.5^{\circ} \mathrm{P}$ and stage II to ca. $4.2^{\circ} \mathrm{P}$. Thus, complete attenuation of wort sugars was not possible in the case of the SCCR system at these residence times. Unlike the FBR system, only $45 \%$ of the total attenuation was achieved in stage I.

Cell Growth and Biomass Production. The growth of the free cells (i.e., the cells that are not immobilized in the carrier) as measured in the liquid samples during the period when the data were collected is depicted in Figure 4. Some remarkable differences between the two types of systems are evident. It can be seen that the total cell counts in stage I of the FBR system (Figure 4a) were the same as those in stage II. Thus, no additional cell growth occurred in the second stage in the FBR system. In the SCCR system, in contrast, a significant cell growth occurred in stage II (Figure 4b). These differences between the two systems are further discussed below. The cell viability remained constant in both the systems throughout the duration of operation (FBR, $(7.5 \pm 2.5) \%$ and $(12.5 \pm 2.5) \%$ dead cells in stages I and II, respectively; SCCR, ca. $3 \%$ in both stages).

In the case of the FBR system, there was a transient increase in the total cell count (TCC) after about 2 

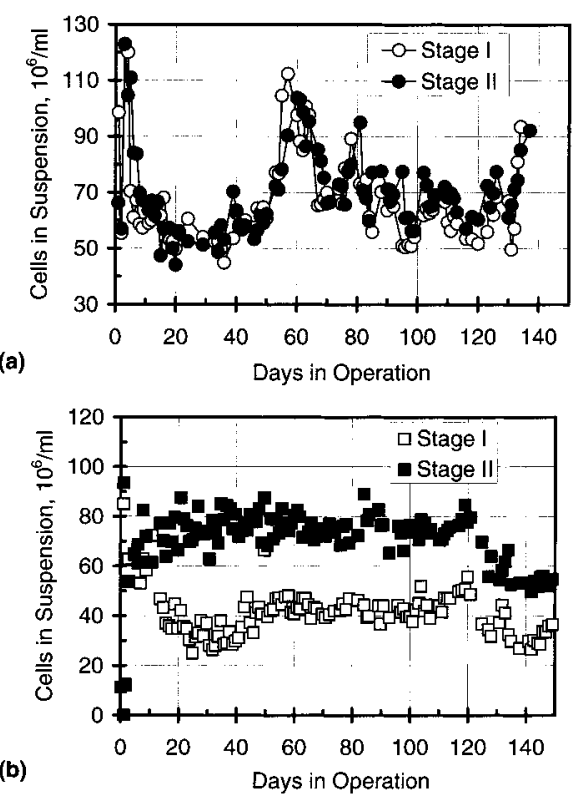

Figure 4. Cell growth. (a) FBR system: The cell concentration in stage II is almost the same as in stage I, indicating that all cell growth occurs in stage I. (b) SCCR system: growth occurs about equally in the two stages.

months of operation (Figure 4a). The cell counts subsequently decreased over a period of time to levels similar to those of the original steady state. We believe that this transient increase in growth occurred due to increased oxygen ingress into the feed wort through the then freshly replaced silicone feed tubing. It is well-known that oxygen can have a dominant effect on the extent of cell growth in beer fermentations. Oxygen is essential for yeast sterol biosynthesis (34-36), energy metabolism, and nutrient transport (37), among others, and therefore for yeast growth and vitality. During the course of this study, it was found that, when newly installed, the silicone elastomer tubing used for feeding FBR stage I nucleates $\mathrm{CO}_{2}$ bubbles in the feed wort (which was slightly carbonated during storage under $\left.\mathrm{CO}_{2}\right)$. The presence of such $\mathrm{CO}_{2}$ bubbles inside the feed tubing constitutes a large sink for oxygen permeating from the ambient environment, leading to a net increase in oxygen input to the bioreactor. Upon prolonged service, the tubing is passivated and $\mathrm{CO}_{2}$ bubble formation is completely eliminated.

Oxygen permeation in the feed to stage II was not an issue in the case of the FBR system because the transfer tubing that harvested fermenting beer from stage I and delivered it to stage II was a large-diameter norprene tubing with poor permeability for oxygen. Also, the large volume of $\mathrm{CO}_{2}$ gas carried al ong with the beer strips most of the oxygen from the beer. The SCCR system was much smaller in capacity and did not need as much oxygen to sustain the same total cell growth; therefore, norprene tubing that had a lower permeability for oxygen was adequate. Unlike the FBR system, both SCCR stages employed the same (norprene) tubing materials; therefore, the amount of oxygen permeating into stage II of this system was similar to that permeating into stage $I$.

The differences in cell growth rates between the two bioreactor systems may have far reaching implications in their performance. Increased cell densities in the reactors can immediately impact the carbohydrate fermentation rates in the reactor. In addition, cell growth determines the extent of wort amino acid (free amino nitrogen) uptake (38) that in turn alters the production
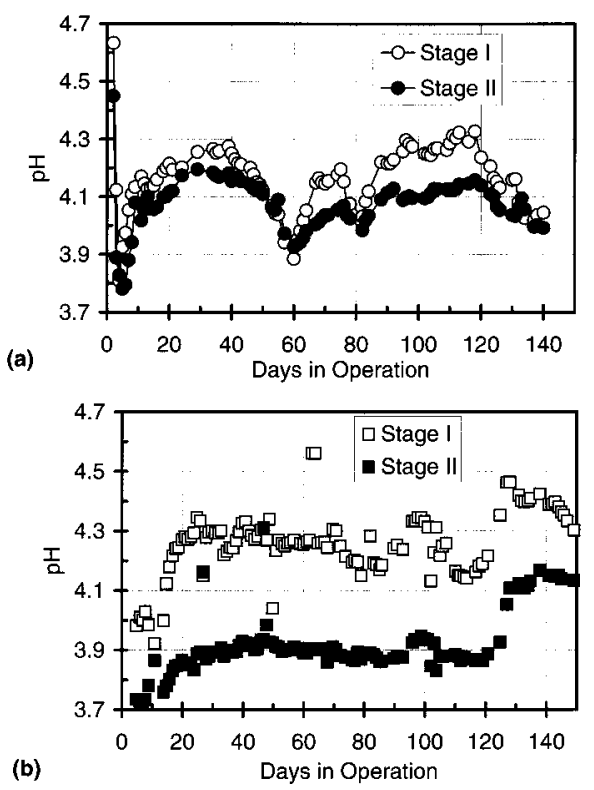

Figure 5. Medium $\mathrm{pH}$. A decrease in $\mathrm{pH}$ correlates with the times of increased growth in either system. (a) FBR system. (b) SCCR system.

of the various intermediates and byproducts of the amino acid metabolic pathways. For example, changes in growth rates can alter the production of organol eptically important higher alcohols (fusel oils), their esters, sulfur dioxide, hydrogen sulfide, and precursors of vicinal diketones (VDKs) ( $\alpha$-acetolactate and $\alpha$-aceto- $\alpha$-hydroxybutyric acid). These aspects could have significant influence on the development of appropriate immobilized yeast systems. For example, Kirin Breweries in J apan employed an aerated CSTR as a first stage where the wort amino acids are removed by the rapidly growing yeast. Little extract is consumed in this stage, and the wort/beer with reduced nitrogen is then fed to a packed bed immobilized yeast bioreactor for fermentation/extract consumption under conditions of minimal biomass growth (39).

Increased amino nitrogen utilization by the yeast during periods of high growth decreases the $\mathrm{pH}$ of the medium accordingly. As seen in Figure 5, the variation in $\mathrm{pH}$ mirrors that of the spurts in growth rates seen in Figure 4 for the two systems.

Cell Loading on the I mmobilization Matrixes. An important variable in any immobilized cell reactor system is the extent of cell colonization of the immobilization matrix. For the FBR system, it was possible to sample the fermentation medium along with some of the beads from the fluidized bed for the determination of cell loading. The cell growth data for the two systems are summarized in Table 1. At the typical operating conditions, it was found that between 14 and $22 \mathrm{~g}$ of cells colonized each bulk liter of glass beads in the FBR system. From these values, it appears that there were about 1.4-2.3 times as many immobilized cells as the free cells in the reactor. Similar analysis showed that the cell loading in the SCCR cartridge was between 8 and $12 \mathrm{~g} / \mathrm{matrix}$. This corresponds to an immobilized cell/free cell ratio of $0.7-1.1$ in stage II of this system. Although others have reported cell loading of up to $20 \mathrm{~g} /$ matrix in this type of a system $(32,40)$, in our studies it was never greater than $12 \mathrm{~g} /$ matrix even with a highly flocculent yeast strain that was similar to the one used in this literature (data not shown). Despite such a level of colonization, the contribution of the immobilized cells 
Table 1. Yeast Concentrations in the Bioreactors

\begin{tabular}{|c|c|c|c|c|}
\hline & \multicolumn{2}{|c|}{$\mathrm{FBR}^{\mathrm{a}}$} & \multicolumn{2}{|c|}{$\mathrm{SCCR}^{\mathrm{b}}$} \\
\hline & stage I & stage II & stage I & stage II \\
\hline $\begin{array}{l}\text { free cells, g of dry wt/L } \\
\text { immobilized cells }{ }^{c} \\
\text { total cells/reactor volume, } \\
\text { a of dry wt/L }\end{array}$ & $\begin{array}{l}4.5 \\
14-22 \\
10.8-14.8\end{array}$ & $\begin{array}{l}4.6 \\
14-22 \\
11.1-14.9\end{array}$ & $\begin{array}{l}2.6 \\
8-12 \\
6.2-7.9\end{array}$ & $\begin{array}{l}5.0 \\
8-12 \\
8.6-10.3\end{array}$ \\
\hline $\begin{array}{l}\text { total immobilized cells/ } \\
\text { total free cells }\end{array}$ & $1.4-2.3$ & $1.4-2.3$ & $1.36-2.0$ & $0.7-1.1$ \\
\hline
\end{tabular}

remained relatively moderate for the fermentation performance of the system as discussed below.

Volumetric Productivity. A useful performance indicator for comparing different reactor systems and configurations is the volumetric productivity $\mathrm{r}_{\mathrm{CHO}}$ expressed as the rate of carbohydrate consumption per unit reactor vol ume. The data from Figure 3 are recalculated for carbohydrate consumption rates and normalized to a unit of reactor volume and summarized in Figure 6.

It can be seen that, for the FBR system (panel a of Figure 6), the productivity in stage I was $2.5-3.0 \mathrm{~g}$ of $\mathrm{CHO} \mathrm{h}-1 \mathrm{~L}^{-1}$, while in stage II, it was ca. $1.2 \mathrm{~g}$ of $\mathrm{CHO}$ $\mathrm{h}^{-1} \mathrm{~L}^{-1}$. Thus, volumetric productivity in stage I was $2-3$ times greater than in stage II, and the majority of fermentation occurred in stage I. The average productivity was approximately $2.0 \mathrm{~g}$ of $\mathrm{CHO} \mathrm{h}^{-1} \mathrm{~L}^{-1}$ for the complete fermentation. Fermentation rates in the SCCR system (panel b, Figure 6) were somewhat similar in the two stages (ca 2.1 and $1.7 \mathrm{~g}$ of $\mathrm{CHO} \mathrm{h}^{-1} \mathrm{~L}^{-1}$ in stages I and II, respectively). The average productivity of 1.9 was again somewhat similar to that of the FBR system. However, there was one important difference-the SCCR system did not produce a completely fermented product; there was typically ca. $4{ }^{\circ} \mathrm{P}$ of carbohydrate (mostly nonfermentable) remaining in stage II. In batch fermentations, wort carbohydrate consumption is a sequential process, occurring in the order glucose, maltose, and mal totriose. Fermentation rates are greatest during the period of glucose metabol ism and decrease progressively when metabolism switches to maltose, and then to maltotriose. In view of such a preferred order of carbohydrate fermentation, we believe that the stage II productivity includes an efficient consumption of maltotriose in addition to glucose and maltose.

In a laboratory batch fermentation with the same wort and yeast used in this study, the maximum carbohydrate fermentation rate is typically about $2.0 \mathrm{~g} \mathrm{~h}^{-1} \mathrm{~L}^{-1}$, with the average being ca. $0.8-1.0 \mathrm{~g} \mathrm{~h}^{-1} \mathrm{~L}^{-1}$ (data not shown) $(41,42)$. A comparison of the free cell fermentation rates in separate fed-batch fermentation experiments conducted at ca. $10^{\circ} \mathrm{P}$ with the same wort and the yeast strain indicated that the free cells contribute about 40$60 \%$ of the total fermentation in stage I of the SCCR system (43). The average productivity (i.e., for total fermentation) in the FBR system is approximately twice the average batch fermentation productivity and actually approximates the peak fermentation rates in a conventional batch system. This productivity advantage for the immobilized systems could be the result of several factors. First, there is no distinct "growth phase" as in a batch fermentation; unlike in the batch fermentation, the wort, when it enters the reactor, is fermented by a high concentration of yeast cells. Second, the yeast cells are al ready acclimated to the medium, and hence there is no "lag". Third, stage II may be rather efficient in fermenting the least preferred carbohydrate, maltotriose. Together with the fermentation by the immobilized yeast
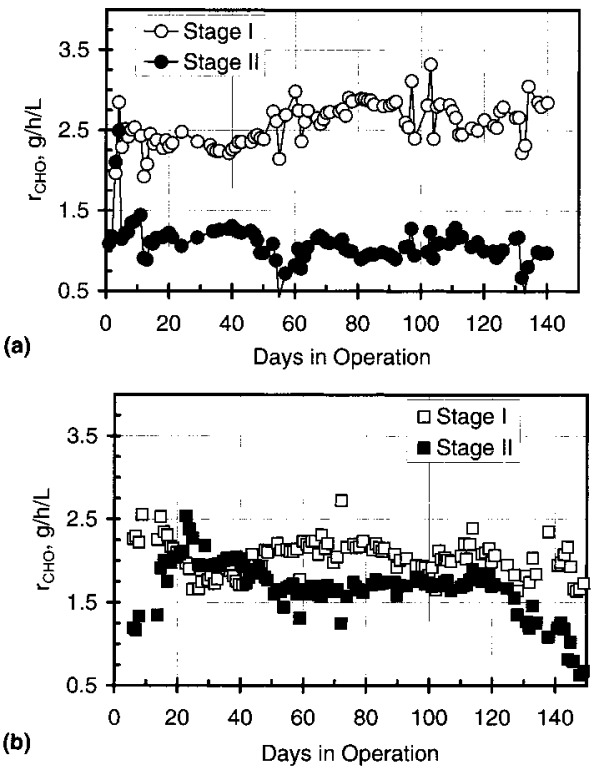

Figure 6. Volumetric productivity of the bi oreactors. Productivities are calculated from the data of Figure 3. The values are expressed as the rate of carbohydrate consumption per unit reactor volume. (a) FBR system. (b) SCCR system. Typical batch fermentation rates for this wort and yeast strain are approximately $2.0 \mathrm{~g} \mathrm{~h}^{-1} \mathrm{~L}^{-1}$ at the peak fermentation period and $0.8-1.0 \mathrm{~g} \mathrm{~h}^{-1} \mathrm{~L}^{-1}$ averaged over the entire fermentation.

cells, the productivity of these immobilized yeast systems is far greater than that of conventional batch fermentation.

Although it is known that sterols and unsaturated fatty acids can partly substitute for oxygen, in modern brewery fermentations, yeast growth is usually limited by the available dissolved oxygen. For the present system, the cell growth yield coefficient $\mathrm{Y}_{\mathrm{x} / \mathrm{O}_{2}}$ is ca. $950 \mathrm{~g}$ of dry cell $\mathrm{s} / \mathrm{g}$ of oxygen. This value is dramatically different from the usual $\mathrm{Y}_{\mathrm{x}_{\mathrm{O}}} \approx 1.0$ expected for energy metabolism using a carbohydrate substrate where respiration accounts for most of the oxygen flux $(44,45)$. Indeed with such microaerobic systems, as in any system with a very large limiting nutrient cell yield coefficient, relative instability is a well-recognized phenomenon in a CSTR operation. For example, large oscillations are seen in biomass concentrations (and thus growth rates) in the case of a magnesium-limited Agrobacterium tumefaciens chemostat culture ( $\mathrm{Y}_{\mathrm{X} / \mathrm{Mg}}$ is typically $300-900 \mathrm{~g}$ of dry cells/g) (46). In our laboratory, separate CSTR experiments set up without the immobilization matrixes lost productivity rapidly due to cell washout. Addition of air/oxygen to the reactor to increase growth improved performance transiently, but the system remained difficult to control (data not shown). Exquisite sensitivity to the level of available oxygen seen as hysteresis and sustained oscillations were described by Grosz and Stephanopoulos in mi cro-aerobic chemostats using yeast for the production of ethanol (47, 48). In aerobic yeast fermentation, the Crabtree effect is generally overcome and most of the available oxygen is used for energy metabolism (respiration), resulting in much smaller yield coefficients $\left(\mathrm{Y}_{\mathrm{x} / \mathrm{O}_{2}} \approx 1.0\right.$ for carbohydrate metabolism) and more stable bioreactor operation.

It is possible to show from the productivity data of the present paper that the carbohydrate fermentation kinetics remained mostly in the reaction-controlled regime (effectiveness factor greater than 0.9), for the 1-2 mm diameter beads (data not shown). Thus, the immobilized cells did not experience any diffusional restrictions, and presumably performed at reasonable specific fermenta- 


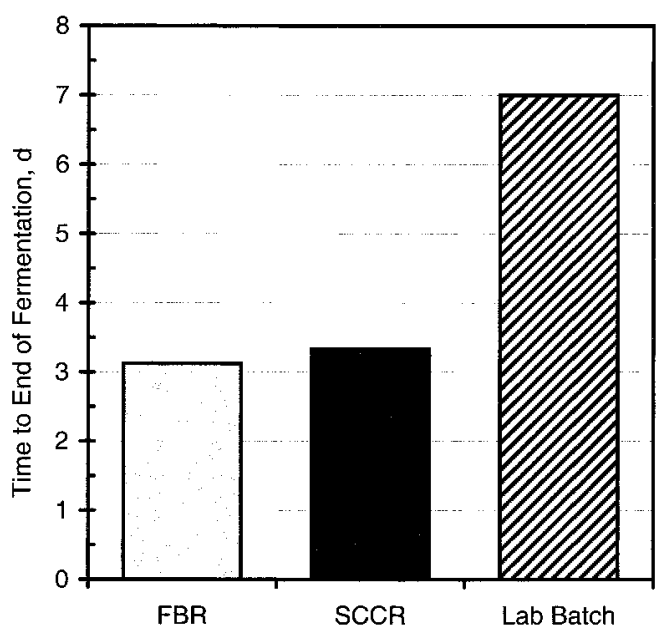

Figure 7. Time to complete fermentation. The immobilized yeast systems complete fermentation in nearly half the time taken by the conventional batch process (a laboratory fermentation). See the text for the definition of the end of a batch fermentation.

tion rates dictated by their physiological state. Despite the observation that the free cells contribute significantly to total fermentation in the immobilized cell reactors, the immobilizing matrix is indispensable for their stable, long-term operation. As compared to a free cell continuous fermentati on system, the immobilized yeast systems are also more robust in recovery after process upsets. After a period of reactor operation at very high dilution ( $\left.D \gg \mu_{X_{\max }}\right)$, the free cells can be washed out of the reactors. Under more favorable conditions, e.g., when the dilution rates are decreased, the cells in the immobilization matrix multiply, shed daughter cells into the medium, and repopulate a steady-state free cell concentration.

Time to Complete Fermentation. In Figure 7, the time (or residence time in the case of the two continuous bioreactors) required to complete fermentation is shown. A batch fermentation is defined to be "complete" when the $\mathrm{CO}_{2}$ evolution rate from fermentation decreases bel ow $10.5 \mathrm{~mL} \mathrm{~L}^{-1} \mathrm{~h}^{-1}$. This criterion is also equivalent to a change of $0.1^{\circ} \mathrm{P}$ in extract in a $24 \mathrm{~h}$ period. To produce a specific amount of product, it takes the immobilized yeast systems only about half the time required for the conventional batch process. Wort as it enters the system is fermented by both the immobilized cells as well as the large numbers of free cells, which results in the apparent high productivity of the immobilized bi oreactor systems. In a batch fermentation in contrast, little extract is fermented until the cell growth is completed (a delay of about $15 \mathrm{~h}$ ), nor is there any contribution to fermentation from the immobilized yeast. During long-term operation, the immobilized yeast systems appear even more attractive because they do not have any significant downtime such as for cleaning, filling, and harvesting cycles that a batch process needs. Thus, there is a clear, practical productivity advantage for the immobilized yeast systems.

Flavor Profiles. During fermentation, significant levels of $\alpha$-acetolactate and $\alpha$-acetohydroxybutyric acidintermediates of the valine and isoleucine biosynthetic pathways-accumulate. These compounds spontaneously decarboxylate to produce the corresponding vicinal diketones (VDKs, mainly diacetyl and 2,3-pentanedione) over time. Accumulation of the VDKs gives rise to varying degrees of "buttery" or "butterscotch" flavors that are considered objectionable in the final product. In a con-

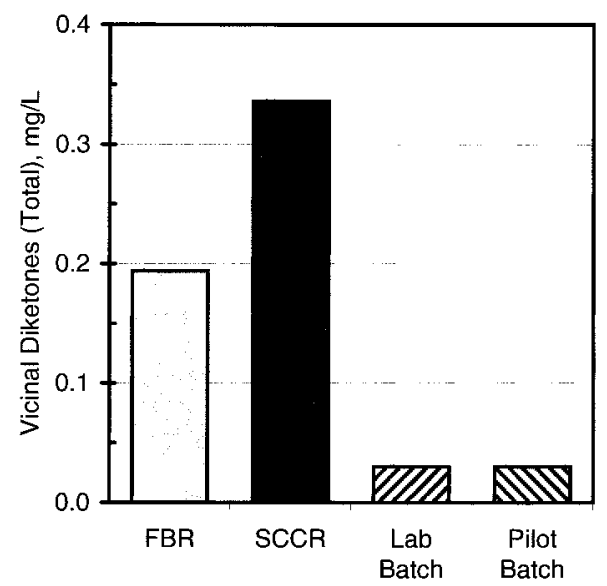

Figure 8. Product flavor profiles: vicinal diketones (VDKs). Both the immobilized yeast systems' products have high levels of VDKs as compared with conventional batch fermentation (lab scale) and a pilot scale batch (unstirred) fermentation.

ventional batch fermentation, the VDKs are assimilated by the yeast during the later stages of fermentation and also perhaps during the beer "aging" in many breweries. In the immobilized yeast systems, due to the shorter hydraulic residence times, the conversion of VDK precursors is usually not complete. Unless the VDKs and their precursors are reduced at this time, significant conversion of the precursors occurs during aging and even in the final packaged product, causing unacceptable flavors. In the context of the current immobilized yeast systems, the production of VDKs is shown in Figure 8. Production of VDKs is lower in the FBR system than in the SCCR system. The taste threshold level of the VDKs at which their flavor becomes objectionable is about $0.1 \mathrm{ppm}$. F or comparison, VDK levels in a conventional (lab) batch product at the end of fermentation are also shown in the last bar graph.

To solve this situation, an accelerated VDK precursor conversion and maturation system was used (49). The product from the reactors was continuously filtered, and the beer passed through a flash pasteurizer at $80^{\circ} \mathrm{C}$, at a residence time of $6 \mathrm{~min}$, and rapidly cooled to ca. $0{ }^{\circ} \mathrm{C}$. This product was fed through a packed bed immobilized yeast bioreactor for VDK assimilation by the yeast. This immobilized yeast maturation column employed porous glass beads similar to the ones used in the FBR system, but of a larger size. The final product obtained after this accelerated maturation step had VDK levels lower than that of a conventional product (lab and pilot scale batch fermentations, as shown in Figure 8). The total residence time in the accelerated maturation system varied be tween 2 and $12 \mathrm{~h}$. These processing steps did not alter the levels of any of the other flavor compounds as verified by the headspace gas chromatography analysis.

Other volatile compounds, notably esters and higher alcohols (fusel oils), impart to a beer its characteristic flavor/aroma profile. Different esters contribute different types of fruity or floral aroma characters to a beer. High levels of fusel alcohols impart a winy character that may or may not be favored depending upon the general type of the beer. Some believe that very high levels of fusel alcohols alter the perception of "smoothness" and "drinkability" characters, and also that they cause headaches for some consumers. Levels of some volatile compounds in products from the different systems are shown in Figure 9. The immobilized yeast systems produced lower levels of total higher alcohols and more of "total esters", of which the relatively flavor-neutral ethyl acetate pre- 


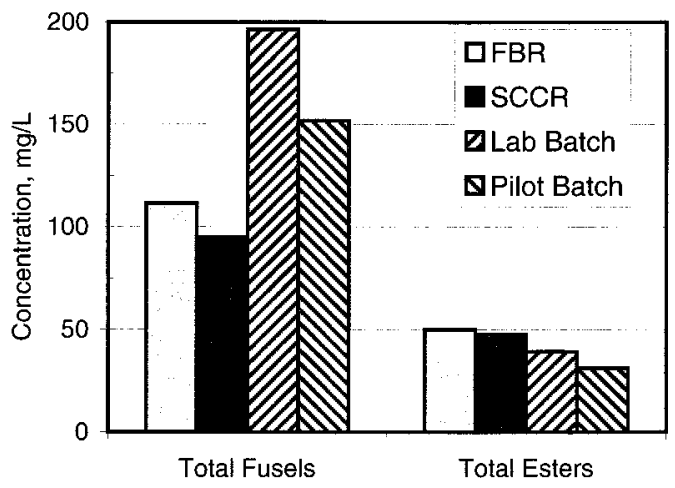

(a)

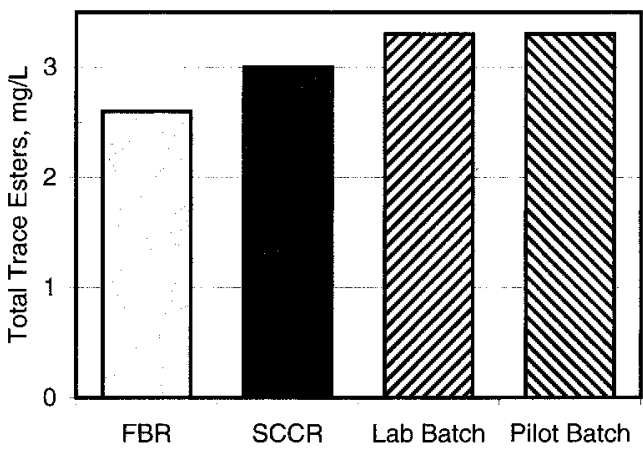

(b)

Figure 9. Product flavor profiles: volatiles. The immobilized system products have higher levels of total esters and lower levels of fusel al cohols. The notation is the same as in Figure 8.

dominates. The immobilized yeast systems also produce slightly lower levels of the flavor active trace esters than the conventional batch product. The finished product from the FBR system was found to be quite likeable upon tasting, but of a different flavor profile than a conventional product.

\section{Conclusions}

We have demonstrated the technological feasibility of immobilized yeast bioreactor systems for continuous beer production. The kinetics of extract consumption in the bioreactors was far superior to that in a conventional batch fermentation process. Between the two systems examined, the kinetics of extract consumption was somewhat similar, but there were clear differences. In the FBR system practically all cell growth occurred in stage I, whereas in the SCCR system, growth occurred in both stages. At similar dilution rates (residence times), the FBR system produced a completely fermented product whereas the SCCR system did not. Although there were some differences within the two immobilized yeast system products, both had a flavor profile different from that of the conventional batch fermentation product. Total yeast biomass production in either system was similar to that of a conventional batch process; therefore, the technology, if implemented at the commercial scale, would not significantly alter the yeast byproduct slate. In stage I of either system, the free and immobilized cells make about equal contribution to fermentation. The levels of vicinal diketones in the reactor products were el evated, requiring an accel erated maturation system to realize the full benefit of improved fermentation rates using the immobilized yeast technology. Due to the fact that the immobilized yeast systems can operate as a continuous process, they provide other advantages such as stable and consistent operation over a long period of time, with minimal operator intervention.

\section{Acknowledgment}

Support and permission to publish this work by Miller Brewing Co. is gratefully acknowledged.

\section{References and Notes}

(1) Stratton, M.; Campbell, S.; Banks, D. Process devel opments in the continuous fermentation of beer. Proceedings, 23rd Convention, Institute of Brewing-Asia Pacific, 1994; pp 96100.

(2) Stewart, E.; Laufer, S. Continuous fermentation in the brewing industry. Am. Brewer 1960, 20.

(3) Cashin, M.-M. Comparative studies of five porous supports for yeast immobilization by adsorption/attachment. J . Inst. Brew. 1996, 102, 5-10.

(4) Inama, L.; Diré, S.; Carturan, G. Entrapment of viable microorganisms by $\mathrm{SiO}_{2}$ sol-gel layers on glass surfaces: trapping, catalytic performance, and immobilization durability of Saccharomyces cerevisiae J . Biotechnol. 1993, 30, 197210.

(5) Isono, Y.; Araya, G.; Hoshino, A. I mmobilization of Saccharomyces cerevisiae for ethanol fermentation on $\gamma$-alumina partides using spray-dryer. Process Biochem. 1995, 30, 743746.

(6) Shindo, S.; Sahara, S.; Watanabe, N.; Koshino, S. Main fermentation with immobilized yeast using fluidized bed bioreactor. Proceedings, 23rd Convention, Institute of Brewing-Asia Pacific, 1994; pp 109-113.

(7) Shinonaga, M.-K.; Kawamura, Y.; Yamane, T. Immobilization of yeast cells with cross-linked chitosan beads. J. Ferment. Bioeng. 1992, 74, 90-94.

(8) O'Reilly, A.; Scott, J. Use of an ion-exchange sponge to immobilize yeast in high gravity apple based (cider) alcoholic fermentations. Biotechnol. Lett. 1993, 15, 1061-1066.

(9) Lorenz, O.; Haulena, F.; Rose, G. Immobilization of yeast cells in polyurethane ionomers. Bi otechnol. Bioeng. 1987, 29, 388-391.

(10) Ogbonna, J .; Liu, Y .-C.; Liu, Y.-K.; Tanaka, H . Loofa (Luffa cylindrica) sponge as a carrier for microbial cell immobilization. J . Ferment. Bioeng. 1994, 78, 437-442.

(11) Mensour, N.; Margaritis, A.; Briens, C.; Pilkington, H.; Russell, I. N ew developments in the brewing industry using immobilized yeast cell bioreactor systems. J . Inst. Brew. 1997, 103, 363-370.

(12) Norton, S.; D'Amore, T. Physiological effects of yeast cell immobilization: applications for brewing. Enzyme Microb. Technol. 1994, 16, 365-375.

(13) Galazzo, J .; Bailey, J . Fermentation pathway kinetics and metabolic flux control in suspended and immobilized Saccharomyces cerevisiae Enzyme Microb. Technol. 1990, 12, $162-172$.

(14) Galazzo, J.; Bailey, J. Growing Saccharomyces cerevisiae in calcium-alginate beads induces cell alterations which accelerate glucose conversion to ethanol. Bi otechnol. Bioeng. 1990, 36, 417-426.

(15) De Becker, L.; Devleminck, S.; Willaert, R.; Baron, G. Reaction and diffusion in gel-membrane reactor containing immobilized cells. Biotechnol. Bioeng. 1992, 40, 322-328.

(16) Willaert, R.; Baron, G. Effectiveness factor calculation for immobilized growing cell systems. Biotechnol. Lett. 1994, 8, 695-700.

(17) Hannoun, B.; Stephanopoulos, G. Diffusion coefficients of glucose and ethanol in cell-free and cell-occupied calciumal ginate membranes. Biotechnol. Bioeng. 1986, 28, 829-835.

(18) Greenshields, R.; Smith, E. Tower fermentation systems and their applications. Chem. Eng. 1971, May, 182-190.

(19) Comberbach, D.; Bu'Lock, J . Continuous ethanol production in gas-lift tower fermentor. Biotechnol. Lett. 1984, 6, $129-134$.

(20) Sousa, M.; Teixeira, J .; Mota, M. Comparative analysis of ethanolic fermentation in two continuous flocculation bioreactors and effect of flocculation additive. Bioprocess Eng. 1994, 11, 83-90.

(21) Yamauchi, Y.; Okamoto, T.; Murayama, H.; Nagara, A.; Kashihara, T.; Nakanishi, K. Beer brewing using an immobilized yeast bioreactor design of an immobilized yeast 
bioreactor for rapid beer brewing system. J . Ferment. Bioeng. 1994, 78, 443-449.

(22) Yamauchi, Y.; Kashihara, T.; Murayama, H.; Nagara, A.; Okamoto, T.; Mawatari, M. Scale-up of immobilized yeast bioreactor for continuous fermentation of beer. MBAA Technol. Q. 1994, 31, 90-94.

(23) Smith, J. Chemical engineering kinetics; McGraw-Hill: New York, 1970.

(24) Levenspiel, O. Chemical reaction engineering; Wiley: New York, 1972

(25) Methods of Analysis, Appendix, Tables related to determinations on wort, beer, and brewing sugars and syrups, American Society of Brewing Chemists, 1985.

(26) Kozulis, J.; Page, H. E. A new universal beer agar medium for the enumeration of wort and beer microorganisms. Proc. Am. Soc. Brew. Chem. 1968, 52-58.

(27) Methods of Analysis, Beer-25 and Beer-29, American Society of Brewing Chemists, 1985.

(28) Breitenbucher, K.; Mistler, M. Fluidized bed fermenter for continuous production of non-alcoholic beer with open-pore sintered glass carriers. Immobilized yeast in the brewing industry; Monograph XXIV, European Brewery Convention symposium, Espoo, Finland, October 1995; pp 77-89.

(29) Pajunen, E.; Grönqvist, A. Immobilized yeast fermentors for continuous lager beer maturation. Proceedings, 23rd Convention, Institute of Brewing-Asia Pacific, 1994; pp 101103.

(30) van De Winkel, L.; van Beveren, P.; Masschelein, C. The application of an immobilized yeast loop reactor to the continuous production of alcohol-free beer. Proceedings of the European Brewing Convention, 23rd Congress, Lisbon, Portugal, 1991.

(31) van DeWinkel, L.; McMurrough, I.; Evers, G.; van Beveren, P.; Masschelein, C. Pilot-Scale evaluation of silicon carbide immobilized yeast systems for continuous alcohol-free beer production. I mmobilized yeast in the brewing industry; Monograph XXIV, European Brewery Convention symposium, Espoo, Finland, October 1995; pp 90-96.

(32) Andries, M.; van Beveren, P.; Goffin, O.; Masschelein, C. Design of a multipurpose immobilized yeast bi oreactor system for application in the brewing process. I mmobilized yeast in the brewing industry; Monograph XXIV, European Brewery Convention symposium, Espoo, Finland, October 1995; pp 134-143

(33) Gill, G.; J ones, W.; Tornabene, T. Continuous ethanol production in a two-stage, immobilized/suspended-cell biore actor. Enzyme Microb. Technol. 1991, 13, 390-399.

(34) Aries, V.; Kirsop, B.; Taylor, G. Yeast lipids. Proc. Eur. Brew. Conv. 1977, 16, 255-266.

(35) Quain, D. Studies on yeast physiology- impact on fermentation performance and product quality. J . I nst. Brew. 1988, 95, 315-323.

(36) O'Connor-Cox, E.; Lodolo, E.; Axcell, B. Mitochondrial relevance to yeast fermentation performance: a review. J . Inst. Brew. 1996, 102, 19-25.
(37) Barnett, J . The utilization of disaccharides and some other sugars by yeasts. Adv. Carbohydr. Chem. Biochem. 1981, 39 347-404.

(38) Inoue, T.; Kashihara, T. The importance of indices related to nitrogen metabolism in fermentation control. MBAA Technol. Q. 1995, 32, 109-113.

(39) Yamauchi, Y.; Okamoto, T.; Murayama, H.; Nagara, A.; Kashihara, T.; Y oshida, M.; Nakanishi, K. Rapid fermentation of beer using an immobilized yeast multistage bioreactor system. Appl. Biochem. Biotechnol. 1995, 53, 245-259.

(40) Masschelein, C.; Andries, M. The Meura-Delta immobilized yeast fermenter for the continuous production of beer. Cerevisia Belg. J . Brew. Biotechnol. 1996, 21, 28-31.

(41) Stassi, P.; Rice, J .; Munroe, J .; Chicoye, E. Use of CO2 evolution rate for the study and control of fermentation. MBAA Technol. Q. 1987, 24, 44-50.

(42) Bromberg, S.; Bower, P.; Duncombe, D.; Fehring, J .; Gerber, L.; Lau, V.; Tata, M. Requirements for zinc, manganese, calcium, and magnesium in wort. J. Am. Soc. Brew. Chem. 1997, 55, 123-128.

(43) Duncombe, D.; Bower, P.; Bromberg, S.; Fehring, J .; Gerber, L.; Lau, V.; Tata, M. The contribution of free cells in an immobilized yeast system. Presented at the Annual Meeting of the American Society of Brewing Chemists, Chicago, IL, 1996.

(44) Nagai, S. Mass and energy balances for microbial growth kinetics. In Advances in Bi ochemical Engineering; Ghose, T., Fiechter, A., Blakebrough, N., Eds.; Springer-Verlag: New York, 1979; Vol. II, p 53.

(45) Bailey, J .; Ollis, D. Bi ochemical enginering fundamentals; McGraw-Hill: New York, 1986.

(46) Kurowski, W.; Fenson, A.; Pirt, S. Stabilization of the glucoside 3-dehydrogenase in Agrobacterium tumefaciens. I. Effect of growth conditions on the enzyme activity and its decay. J . Gen. Microbiol. 1973, 75 (2), xv.

(47) Grosz, R.; Stephanopoulos, G. Physiological, biochemical, and mathematical studies of micro-aerobic continuous ethano fermentation by Saccharomyces cerevisiae. I: hysteresis, oscillations, and maximum specific ethanol productivities in chemostat culture. Biotechnol. Bioeng. 1990, 36, 1006-1019.

(48) Grosz, R.; Stephanopoulos, G. Physiological, biochemical, and mathematical studies of micro-aerobic continuous ethano fermentation by Saccharomyces cerevisiae. II: intracellular metabolite and enzyme assays at steady-state chemostat cultures. Biotechnol. Bioeng. 1990, 36, 1020-1029.

(49) Hyttinen, I.; Kronl of, J .; Hartwal I, P. Use of porous glass at Hartwall brewery in the maturation of beer with immobilized yeast. I mmobilized yeast in the brewing industry; Monograph XXIV, European Brewery Convention symposium, Espoo, Finland, October 1995; pp 55-61.

Accepted December 4, 1998.

BP980109Z 